\title{
Predictors of transfusion outcomes in pediatric complex cranial vault reconstruction: a multicentre observational study from the Pediatric Craniofacial Collaborative Group Les prédicteurs des besoins transfusionnels lors d'une reconstruction de la voûte crânienne complexe chez l'enfant : une étude observationnelle multicentrique du Groupe collaboratif craniofacial pédiatrique
}

\author{
Patrick G. Fernandez, MD • Brad M. Taicher, DO, MBA • Susan M. Goobie, MD, FRCPC • \\ Meera Gangadharan, MBBS, FAAP • H. Mayumi Homi, MD • Jane A. Kugler, MD, FAAP • \\ Rochelle Skitt, MD • Lingyu Cai, MS • Marcia Polansky, ScD, MS, MSW • \\ Paul A. Stricker, MD • The Pediatric Craniofacial Collaborative Group
}

Received: 24 August 2018/Revised: 4 December 2018/Accepted: 8 December 2018/Published online: 14 February 2019

(c) Canadian Anesthesiologists' Society 2019

\begin{abstract}
Purpose Pediatric patients undergoing complex cranial vault reconstruction (CCVR) are at risk of significant perioperative blood loss requiring blood product transfusion. Minimizing allogeneic blood product
\end{abstract}

Collaborators of the Pediatric Craniofacial Collaborative Group are listed in "Acknowledgements".

Electronic supplementary material The online version of this article (https://doi.org/10.1007/s12630-019-01307-w) contains supplementary material, which is available to authorized users.

P. G. Fernandez, MD $(\bowtie) \cdot$ R. Skitt, MD

Section of Pediatric Anesthesiology, Department of Anesthesiology, Children's Hospital Colorado, University of Colorado, 13123 E. 16th Ave, Box 090, Aurora, CO, USA

e-mail: patrick.fernandez@childrenscolorado.org

B. M. Taicher, DO, MBA · H. M. Homi, MD

Department of Anesthesiology, Division of Pediatric

Anesthesiology, Duke University Medical Center, Durham, NC, USA

\section{S. M. Goobie, MD, FRCPC}

Department of Anesthesiology, Perioperative \& Pain Medicine, Harvard Medical School, Boston Children's Hospital, Boston,

MA, USA

\section{Gangadharan, MBBS, FAAP}

Department of Anesthesiology and Critical Care, University of Texas Medical Branch, Galveston, TX, USA transfusion is an important goal because of the associated risks and cost. The impact of patient and surgical variables on transfusion is unknown in this population. Our primary aim was to examine relationships between demographic and perioperative variables and blood product transfusion outcomes in CCVR.

Methods The multicentre Pediatric Surgery Perioperative Registry was checked for children undergoing CCVR between June 2012 and September 2016. Univariable and multivariable analyses were performed examining patient,

J. A. Kugler, MD, FAAP

Department of Anesthesiology, University of Nebraska

Children's Hospital and Medical Center, Omaha, NE, USA

L. Cai, MS · M. Polansky, ScD, MS, MSW

Department of Epidemiology and Biostatistics, Dornsife School of Public Health, Drexel University, Philadelphia, PA, USA

P. A. Stricker, MD

The Children's Hospital of Philadelphia, Department of Anesthesiology and Critical Care Medicine, Perelman School of Medicine, Perelman School of Medicine at the University of Pennsylvania, Philadelphia, PA, USA 
procedure, and blood conservation variables and their relationship to three outcomes: intraoperative red blood cell-containing product (RBC-CP) transfusion, total perioperative blood donor exposures, and transfusionfree hospitalization.

Results The registry search returned data from 1,814 cases. Age and surgical duration were the only variables significantly associated with all three outcomes studied. Predictors of reduced RBC-CP transfusion included lower American Society of Anesthesiologists (ASA) physical status and antifibrinolytic administration. Total cranial vault reconstruction, intraoperative vasoactive infusion, and presence of a tracheostomy predicted increased donor exposures. Increased body weight, higher preoperative hematocrit, and utilization of intraoperative cell saver and transfusion protocols were associated with transfusion-free hospitalization.

Conclusion Clinical factors associated with increased allogeneic blood product transfusion in pediatric CCVR include: age $\leq 24$ months, ASA status $\geq I I I$, preoperative anemia, prolonged surgical duration, lack of intraoperative antifibrinolytic use, lack of intraoperative cell saver use, and the lack of transfusion protocols.

\section{Résumé}

Objectif Les patients pédiatriques subissant une reconstruction complexe de la voûte crânienne courent un risque de pertes sanguines périopératoires importantes nécessitant la transfusion de produits sanguins. La minimisation de la transfusion de produits sanguins allogènes constitue un objectif majeur étant donné les risques et les coûts associés. L'impact des variables liées au patient et à la chirurgie sur la transfusion est inconnu dans cette population. Notre objectif principal était d'examiner les liens entre les variables démographiques et périopératoires, et les résultats des transfusions sanguines suite à une reconstruction complexe de la voûte crânienne.

Méthode Le Registre périopératoire multicentrique de chirurgie pédiatrique (Pediatric Surgery Perioperative Registry) a été consulté afin d'en extraire les dossiers de tous les enfants ayant subi une reconstruction complexe de la voûte crânienne entre juin 2012 et septembre 2016. Des analyses univariées et multivariées ont été réalisées et ont examiné les variables concernant les patients, l'intervention et la conservation du sang ainsi que les relations entre ces données et trois critères : la transfusion peropératoire de produits contenant des érythrocytes, l'exposition durant toute la période périopératoire aux dons de sang, et l'hospitalisation sans transfusion.

Résultats L'examen du Registre a permis d'extraire les données de 1814 cas. L'âge et la durée de la chirurgie étaient les deux seules variables à afficher une association significative aux trois critères à l'étude. Les prédicteurs d'une transfusion réduite d'érythrocytes étaient un statut physique ASA (American Society of Anesthesiologists) plus bas et l'administration d'agents antifibrinolytiques. La reconstruction totale de la voûte crânienne, la perfusion peropératoire d'agents vasoactifs et la présence d'une trachéostomie constituaient des prédicteurs d'exposition plus importante aux dons de sang. Un poids corporel accru, un hématocrite préopératoire plus élevé et l'utilisation de systèmes d'autotransfusion peropératoire et de protocoles de transfusion étaient associés à une hospitalisation sans transfusion.

Conclusion Les facteurs cliniques associés à une augmentation des transfusions de produits sanguins allogènes dans les cas de reconstruction complexe de la voûte crânienne chez l'enfant sont : un âge $\leq 24$ mois, un statut ASA $\geq I I I$, une anémie préopératoire, la durée prolongée de la chirurgie, l'absence d'utilisation peropératoire d'antifibrinolytiques, l'absence d'utilisation de systèmes d'autotransfusion peropératoire, et l'absence de protocoles de transfusion.

Pediatric patients undergoing complex cranial vault reconstruction (CCVR) are at risk of significant blood loss and perioperative transfusion. Minimizing blood loss and blood product transfusion is an important goal given the risks and costs of allogeneic blood transfusion. ${ }^{1-6}$ Numerous blood management strategies have been employed in craniosynostosis surgery, including antifibrinolytics, cell saver, preoperative erythropoietin, acute preoperative normovolemic hemodilution, and the use of restrictive transfusion protocols. The strength of evidence supporting the efficacy and safety of these techniques varies, while knowledge of the impact of other patient and surgical factors on perioperative transfusion, such as patient age, American Society of Anesthesiologists (ASA) physical status, surgical duration, or intraoperative complications, is generally lacking. ${ }^{7}$

In 2011, a consortium of international collaborators from the United States and Canada formed the Pediatric Craniofacial Collaborative Group under the auspices of the Society for Pediatric Anesthesia. This group then established the Pediatric Craniofacial Surgery Perioperative Registry (PCSPR), which has become the largest pediatric craniofacial surgery registry worldwide. It was designed to collect data pertaining to the perioperative course, management, and outcomes in this patient population. A further goal was to foster multicentre research and quality improvement of pediatric anesthesia for reconstructive craniofacial surgery. 
We conducted this study to evaluate the relationships between demographic and perioperative variables and transfusion outcomes of CCVR in the multicentre PCSPR; we have not previously examined variables associated with transfusion outcomes using this database. Three outcomes were evaluated: intraoperative red blood cell-containing product (RBC-CP) transfusion, total perioperative blood donor exposures, and the occurrence of an allogeneic transfusion-free hospitalization course. We hypothesized that patient-related variables (e.g., age, weight, ASA physical status), procedure-related variables (procedure type, surgical duration, redo operation) and specific blood management techniques (use of antifibrinolytics, cell saver, and transfusion protocols) would be independently associated with these transfusion outcomes. The primary aim of this study was to report independent predictors of the transfusion outcomes mentioned.

\section{Methods}

We searched the PCSPR for subjects undergoing CCVR. Complex cranial vault reconstruction was defined as fronto-orbital advancement/anterior cranial vault reconstruction, middle/posterior cranial vault reconstruction, or total cranial vault reconstruction. All procedures involved a craniotomy. Neuro-endoscopic procedures, spring-mediated cranioplasties, and modified Pi procedures were excluded. Data extracted included demographic and surgical data, fluid and transfusion data, perioperative management data, and complications. The study analysis plan was submitted to the Pediatric Craniofacial Collaborative Group scientific review committee and approved prior to the conduct of the analysis. Appropriate institutional review board (IRB)/ research ethics committee approval was obtained at each study site as well as written informed consent when required; at some study sites, the requirement for written informed consent was waived by the IRB. The study was conducted in accordance with STROBE guidelines. ${ }^{8}$

\section{Pediatric craniofacial surgery perioperative registry}

Participating institutions began entering data following local institutional ethical review board or equivalent approval. Study data were collected and managed using REDCap electronic data capture tools hosted at the Children's Hospital of Philadelphia. ${ }^{9}$ Data entry began on June 25, 2012. A de-identified dataset with data through to September 30, 2016 was analyzed. Individual institutions were represented using an institution code and were not identifiable.
Data collection, entry, and validation

Thirty-three institutions contributed data over the study time period. Sites were required to provide quarterly reports quantifying case capture rates to avoid reporting bias. The median $\left(25^{\text {th }}, 75^{\text {th }}\right.$ interquartile range) reported case capture rate across all participating institutions was $100 \%(98 \%, 100 \%)$. All participating institutions were required to report data collection and auditing processes to ensure accuracy. ${ }^{10}$ Perioperative blood management strategies captured by the registry included the preoperative use of erythropoietin, the intraoperative use of antifibrinolytics (tranexamic acid or aminocaproic acid), deliberate hypotension, cell saver utilization, and acute preoperative normovolemic hemodilution. Intraoperative and postoperative transfusion protocols were also used.

In addition to the above, the study's principal investigator at the Data Coordinating Center audited data prior to analysis. This included scrutinizing cases for omissions of critical data (e.g., age, weight) and identifying outlier data. Cross-validation of data within individual records was performed to optimize data accuracy. Queries based on omissions, outliers, and discrepancies identified through this process were aggregated and sent to site investigators for rectification.

\section{Outcomes and statistical analysis}

Demographic data and data describing perioperative management were analyzed using descriptive statistics. Our primary objective was to use univariable and multivariable analysis to identify independent factors associated with three transfusion outcomes: total perioperative blood donor exposures, total volume of intraoperative RBC-CPs, and the occurrence of a transfusion-free hospital course. Red blood cellcontaining products included packed red blood cells (PRBCs), whole blood, and reconstituted blood composed of PRBCs and fresh frozen plasma (FFP). ${ }^{11}$ Hemostatic blood products included non-reconstituted FFP, cryoprecipitate, and platelets.

Independent variables in the analyses included age, weight, sex, race, ethnicity, ASA physical status, preoperative tracheostomy presence, procedure category, cranial distractor placement, history of prior craniofacial surgery, preoperative evidence of elevated intracranial pressure, preoperative hematocrit, use of deliberate hypotension, use of intraoperative cell saver, antifibrinolytic administration (tranexamic acid or aminocaproic acid), use of a standardized protocol to guide either intraoperative or postoperative red cell transfusion, diagnosis of syndromic craniosynostosis or craniosynostosis with three or more sutures involved, 
duration of surgery, intraoperative administration of a vasopressor infusion, occurrence of intraoperative hypothermia (nadir temperature of $<35^{\circ} \mathrm{C}$ ), hypothermia on arrival to the intensive care unit or recovery room $(<$ $35^{\circ} \mathrm{C}$ ), and whether or not one or more major intraoperative cardiorespiratory complications occurred. Major intraoperative cardiorespiratory complications were specific itemized data elements on the registry case report form that were identified prior to analysis. These complications included administration of an intravenous epinephrine bolus, cardiac arrest (defined as any case in which chest compressions were initiated), suspected venous air embolism with cardiovascular collapse, dural venous sinus bleed, suspected transfusion reaction, pulmonary edema, and re-intubation in the operating room.

Data measured on a continuous scale were presented as mean (standard deviation [SD]) or median [interquartile range (IQR)]; categorical variables were presented as frequencies and percentages. Univariable and multivariable analyses were performed for variables potentially associated with the three outcomes described above. For univariable analyses of intraoperative RBC-CP volume and total perioperative blood donor exposure outcomes, the Wilcoxon-Mann-Whitney test was used for dichotomous independent variables and the Kruskal-Wallis test was used for multi-level independent variables. Independent variables with a univariable significance of $P<0.1$ were included in the multivariable model. Because three outcomes were evaluated, a corrected $P$ value of $<$ $0.0167(0.05 / 3)$ was considered statistically significant for the multivariable analysis. For the volume of intraoperative $\mathrm{RBC}-\mathrm{CP}$ and total perioperative blood donor exposure outcomes, multivariable analysis was performed using a generalized linear mixed effect negative binomial model accounting for the effect of institution with a random effect. For the transfusion-free hospital course outcome, the Chi-square test or Fisher's exact test (when the expected counts were less than 5) was used in the univariable analysis. Logistic regression was used in the multivariable analysis for this binary outcome. For the multivariable analyses, case wise deletion was employed in cases of missing data (available as Electronic Supplementary Material; eTable). Statistical analysis was done with the statistical package SAS version 9.4 (SAS Institute, Cary, NC, USA).

\section{Results}

\section{Demographics}

Search of the PCSPR yielded 1,814 subjects from 33 institutions; $75 \%(1,377)$ of these were under 24 months of age (infant group). Detailed demographic data are presented in Table 1. Single-suture metopic and sagittal craniosynostosis were the most common diagnoses. Anterior cranial vault reconstruction/fronto-orbital advancements accounted for greater than $60 \%$ of cases. Craniofacial reoperation accounted for $20 \%$ of cases for all ages and $11 \%$ of cases in the infant group.

Intraoperative blood product transfusion

Intraoperative transfusion data for specific blood products are presented in Table 2. One thousand five hundred and ninety-two $(88 \%)$ of CCVR patients were transfused a mean (SD) volume of $29.7(25.9) \mathrm{mL} \cdot \mathrm{kg}^{-1}$ of allogeneic RBC-CP intraoperatively. Fourteen percent of all patients received an autologous erythrocyte transfusion from intraoperative cell saver (similar in both age groups). With respect to hemostatic blood products, discrete FFP transfusion was the most common, being administered to $22 \%$ of all patients. Platelets and cryoprecipitate were transfused relatively infrequently $(2 \%$ and $3 \%$ of cases, respectively).

Intraoperative RBC-containing product transfusion outcome

Univariable and multivariable analyses of selected independent variables and their relationship to intraoperative $\mathrm{RBC}-\mathrm{CP}$ transfusion are presented in Table 3, with variables organized into three categories: patient variables, procedure variables, and blood conservation variables. Patient variables independently associated with increasing intraoperative RBC-CP transfusion included younger age, decreasing weight, and increasing ASA physical status. Procedure-related variables that were associated with increasing intraoperative $\mathrm{RBC}-\mathrm{CP}$ transfusion in multivariable analysis included procedures not involving distractor placement, longer surgical duration, use of a vasoactive infusion intraoperatively, and the occurrence of a major intraoperative cardiorespiratory complication. Lack of antifibrinolytic administration was the only blood conservation variable independently associated with higher RBC-CP transfusion.

Blood product donor exposure outcome

Univariable and multivariable analyses for variables associated with total perioperative blood donor exposures are shown in Table 4. Younger patient age and the presence of a tracheostomy were the only patient variables that independently correlated with increased donor exposures. Procedural variables that were 
Table 1 Patient demographic data

\begin{tabular}{|c|c|c|}
\hline Variable $^{a}$ & All ages & $\leq 24$ months \\
\hline Number of subjects & 1,814 & 1,377 \\
\hline Number of institutions represented & 33 & 33 \\
\hline \# of cases by institution & $41[16-78]$ & $36[12-53]$ \\
\hline Age (months) & $23.7(30.6)$ & $10.6(5.0)$ \\
\hline Weight (kg) & $12.0(8.9)$ & $9.0(2.6)$ \\
\hline Sex (Male/female) & $1,104 / 710$ & $837 / 540$ \\
\hline \multicolumn{3}{|l|}{ Race: } \\
\hline White/Caucasian & $1,315(73 \%)$ & $1,040(76 \%)$ \\
\hline Black/African American & $198(11 \%)$ & $115(8.5 \%)$ \\
\hline Asian & $53(3 \%)$ & $38(3 \%)$ \\
\hline Other & $228(13 \%)$ & $168(12 \%)$ \\
\hline Not recorded & $20(1 \%)$ & $16(1 \%)$ \\
\hline \multicolumn{3}{|l|}{ Diagnosis: } \\
\hline Sagittal & $417(23 \%)$ & $317(23 \%)$ \\
\hline Metopic & $384(21 \%)$ & $352(26 \%)$ \\
\hline Syndromic & $275(15 \%)$ & $165(12 \%)$ \\
\hline Unicoronal & $272(15 \%)$ & $241(18 \%)$ \\
\hline Multiple ( $\geq 3$ sutures) & $174(10 \%)$ & $93(7 \%)$ \\
\hline Bicoronal & $94(5 \%)$ & $74(5 \%)$ \\
\hline Lambdoid & $54(3 \%)$ & $50(4 \%)$ \\
\hline Sagittal and metopic & $47(3 \%)$ & $34(2 \%)$ \\
\hline Sagittal and unicoronal & $18(1 \%)$ & $8(0.6 \%)$ \\
\hline Sagittal and lambdoid & $16(0.9 \%)$ & $10(0.7 \%)$ \\
\hline Metopic and unicoronal & $11(0.6 \%)$ & $9(0.7 \%)$ \\
\hline Unicoronal and lambdoid & $3(0.2 \%)$ & $2(0.1 \%)$ \\
\hline Other/not recorded & $49(3 \%)$ & $22(1.6 \%)$ \\
\hline \multicolumn{3}{|l|}{ Procedure category: } \\
\hline $\begin{array}{l}\text { Anterior cranial vault/ } \\
\text { fronto-orbital advancement }\end{array}$ & $1,128(62 \%)$ & $888(64 \%)$ \\
\hline Mid/posterior cranial vault & $489(27 \%)$ & $373(27 \%)$ \\
\hline Total cranial vault & $197(11 \%)$ & $116(8 \%)$ \\
\hline Distractor placement & $214(12 \%)$ & $137(10 \%)$ \\
\hline Prior craniofacial surgery & $370(20 \%)$ & $147(11 \%)$ \\
\hline Craniosynostosis syndrome $^{b}$ & $278(15 \%)$ & $167(12 \%)$ \\
\hline Tracheostomy present & $55(3 \%)$ & $32(2 \%)$ \\
\hline $\begin{array}{l}\text { Preoperative evidence of } \\
\text { elevated intracranial pressure }\end{array}$ & $252(14 \%)$ & $84(6 \%)$ \\
\hline Preoperative hematocrit (\%) & $35.7(3.3)$ & $35.3(3.2)$ \\
\hline $\mathrm{ASA}^{c}$ physical status & II (II-III) & II (II-II) \\
\hline Plastic surgeon operated & $1,760(97 \%)$ & $1,327(96 \%)$ \\
\hline Neurosurgeon operated & $1,805(99 \%)$ & $1,372(99 \%)$ \\
\hline Other discipline procedure performed & $95(6 \%)$ & $61(5 \%)$ \\
\hline
\end{tabular}

${ }^{a}$ Data presented as median [interquartile range] for \# of cases by institution, ASA physical status. Data presented as mean (standard deviation) for age, weight, and preoperative hematocrit. All other variables reported as $n$ and $n$ (\%)

${ }^{b}$ Craniosynostosis syndrome included Apert, Crouzon, Pfieffer, SaethreChotzen, Muenke, Antley-Bixler, and Carpenter syndromes

${ }^{c}$ ASA $=$ American Society of Anesthesiologists = I (normal healthy patient), II (patient with mild systemic disease), III (patient with severe systemic disease), or IV (patient with severe systemic disease that is a constant threat to life) associated with increasing blood donor exposures in multivariable analysis included procedures not involving distractor placement, longer duration of surgery, vasoactive infusion administration, and total cranial vault reconstruction ( $v s \quad \mathrm{mid} /$ posterior cranial vault reconstruction). None of the blood conservation variables examined were independently associated with this outcome.

Transfusion-free hospital course outcome

Univariable and multivariable analyses for the binary transfusion-free hospital course outcome are presented in Table 5. Patient-related variables independently associated with this outcome included age greater than 24 months (odds ratio [OR], 4.5; 95\% confidence interval [CI], 2.2 to 9.14), weight greater than $11 \mathrm{~kg}$ (OR, 3.5; 95\% CI, 1.6 to 7.9), ASA physical status III-IV (OR, 0.42; 95\% CI, 0.25 to 0.72 ), and preoperative hematocrit greater than 36 (OR, 2.7; $95 \% \mathrm{CI}, 1.7$ to 4.2 ). Procedure variables that were significantly associated with the occurrence of a transfusion-free course in multivariable analysis included shorter duration of surgery, while total cranial vault reconstruction was associated with a decreased likelihood of this outcome (OR, $0.32 ; 95 \% \mathrm{CI}, 0.14$ to 0.75 , vs $\mathrm{mid} /$ posterior cranial vault reconstruction). With respect to blood conservation variables, intraoperative red cell transfusion was associated with a lower likelihood of a transfusion-free course (OR, 0.10; 95\% CI, 0.05 to 0.21 ), while intraoperative cell saver use (OR, 4.62; 95\% CI, 2.8 to 7.7) and postoperative transfusion protocols (OR, 2.23; $95 \% \mathrm{CI}, 1.3$ to 3.8 ) were independently predictive of a transfusion-free hospital course.

\section{Discussion}

Significant variability exists in the amount of bleeding and transfusion in pediatric CCVR, ranging from massive intraoperative transfusion to a transfusion-free hospitalization. ${ }^{10}$ We evaluated patient, surgical, and blood conservation variables and three perioperative transfusion outcomes in a large multicentre pediatric CCVR dataset to identify independent predictors of transfusion outcomes. The vast majority (88\%) of patients were transfused with a mean RBC-CPs transfusion volume of $30 \mathrm{~mL} \cdot \mathrm{kg}^{-1}$. In multivariable analysis, patient age and surgical duration were the only independent variables associated with all three outcomes. Conversely, prior craniofacial surgery, elevated intracranial pressure, syndromic or multi-suture craniosynostosis, intraoperative hypothermia, sex, race, and ethnicity were not associated with these outcomes. 
Table 2 Intraoperative transfusion data

\begin{tabular}{|c|c|c|c|c|}
\hline & \multicolumn{2}{|c|}{ All ages $(n=1,814)$} & \multicolumn{2}{|c|}{$\leq 24$ months $(n=1,377)$} \\
\hline & $n(\%)$ Receiving & Volume $^{a}\left(\mathrm{~mL} \cdot \mathrm{kg}^{-1}\right)$ & $n(\%)$ Receiving & Volume $^{a}\left(\mathrm{~mL} \cdot \mathrm{kg}^{-1}\right)$ \\
\hline RBC-containing product & $1,592(88 \%)$ & $29.7(25.9)$ & $1,245(90 \%)$ & $32.3(26.7)$ \\
\hline $\mathrm{PRBCs}^{b}$ & $1,335(74 \%)$ & $30.7(20.7)$ & $1,076(78 \%)$ & $31.9(20.8)$ \\
\hline Reconstituted blood ${ }^{b}$ & $79(4 \%)$ & $63.6(35.8)$ & $57(4 \%)$ & $72.8(36.5)$ \\
\hline Whole blood & $178(10 \%)$ & $44.8(27.5)$ & $112(8 \%)$ & $53.1(29.1)$ \\
\hline $\mathrm{FFP}^{b}$ & $394(22 \%)$ & $26.8(18.1)$ & $319(23 \%)$ & $27.6(17.7)$ \\
\hline Platelets & $56(3 \%)$ & $16.8(10.9)$ & $42(3 \%)$ & 18.4 (12) \\
\hline Cryoprecipitate & $37(2 \%)$ & $5.9(7.4)$ & $28(2 \%)$ & $7.4(8)$ \\
\hline Cell saver & $246(14 \%)$ & $7.8(12.5)$ & $188(13 \%)$ & 8.7 (14) \\
\hline
\end{tabular}

${ }^{a}$ Volume data presented as mean (standard deviation). Volume data are reported for those patients who received the blood product

${ }^{b}$ Number of patients and volumes administered of PRBCs and FFP does not reflect PRBC or FFP component of reconstituted blood. Similarly, data reported for reconstituted blood includes PRBCs and FFP that are not included in the data for these individual components. FFP $=$ fresh frozen plasma; $\mathrm{PRBC}=$ packed red blood cells; $\mathrm{RBC}=$ red blood cells

Intraoperative RBC-containing product transfusion

We found that younger age, decreasing weight, and higher ASA physical status were each independently associated with increased intraoperative RBC-CP transfusion. This inverse relationship between age and weight with transfusion is consistent with prior reports. ${ }^{12-15}$ The association between higher ASA physical status and increased transfusion has not been previously reported in CCVR. While age and weight are not directly modifiable, our data suggest the possibility that when appropriate, performing surgery in older children may be a strategy to reduce transfusion. Our findings suggest that increased transfusion requirements might be anticipated in younger, smaller, and more medically complex patients.

Surgical variables associated with increased intraoperative transfusion included longer operations, surgeries without distractor placement, and the occurrence of a major intraoperative cardiorespiratory event or intraoperative vasoactive infusion administration. The correlation of distractor placement with less transfusion is consistent with the less complex nature of these procedures. The association of longer operations with increased transfusion has been described. ${ }^{12-14}$ The underpinnings of this relationship are unclear; for example, it is unknown whether it relates to procedure complexity, or if the operations are longer because more time is required to achieve hemostasis.

Intraoperatively, both the occurrence of a major cardiorespiratory complication and administration of a vasoactive infusion were associated with increased transfusion. We suspect that this association was observed because patients with more hemorrhage (and therefore transfusion) were more likely to develop hypotension requiring a vasoactive infusion and/or suffer a related complication.
Antifibrinolytic administration was the only blood conservation variable associated with decreased intraoperative transfusion. Antifibrinolytic administration is the only readily modifiable variable we studied that was associated with transfusion requirements. In the context of the evidence supporting antifibrinolytic efficacy and safety in CCVR, our findings support more widespread use of antifibrinolytic agents in these children. ${ }^{16-20}$

\section{Perioperative blood donor exposures}

Because CCVR may entail postoperative transfusion, we studied total blood donor exposures to capture the entire perioperative course. Additionally, this outcome captures hemostatic blood products not included in the intraoperative RBC-CP outcome. Demographic variables associated with increased blood donor exposures included age over 24 months and preoperative tracheostomy. It is likely that tracheostomy presence is indicative of increased patient complexity in this outcome; similar to increased ASA status. Indeed, greater ASA status was associated with increased blood donor exposure in univariable analysis but fell out following multivariable analysis. Lower weight did not predict blood donor exposures despite its association with higher intraoperative transfusion volumes. This makes sense given that a standard unit of PRBC (i.e., one blood donor exposure) represents a progressively increasing volume (in $\mathrm{mL} \cdot \mathrm{kg}^{-1}$ ) as patient weight decreases.

Similar to the intraoperative RBC-CP transfusion outcome findings, longer operations and vasoactive infusion administration were associated with increased perioperative donor exposures. Total cranial vault reconstruction was associated with more donor exposures, an expected finding given the greater extent and 
Table 3 Univariable and multivariable analysis for the outcome "intraoperative red blood cell-containing product transfusion ( $\mathrm{mL} \cdot \mathrm{kg}^{-1}$ )" among all age patients

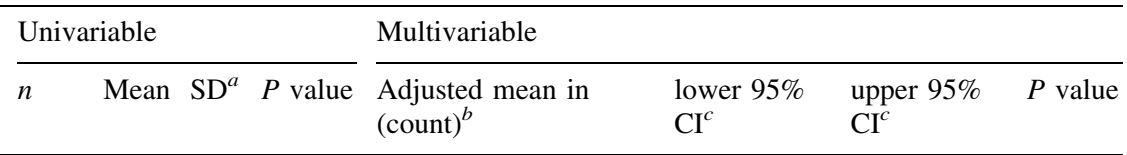

\section{Patient variable}

Age

$\leq 24$ months

$>24$ months

Weight $(\mathrm{kg})$ tertile
1 (3.2-8.6)
2 (8.57-10.9)
$3(11-129)$

Sex

$$
\text { Female }
$$

Male

\section{Race}

Black/African American

Other

White

Ethnicity

Non-Hispanic

Hispanic

ASA physical status

I-II

3-4

Tracheostomy

No

Yes

Preoperative elevated ICP

No

Yes

Preoperative hematocrit median split (\%)

Below median (22-35)

Above median (36-52)

Syndromic/multi-suture synostosis

No

Yes

Intraoperative hypothermia $(\mathrm{T}<35)$

No

Yes

Hypothermia on arrival to ICU/PACU $(\mathrm{T}<35)$

No

Yes

Procedure variable

Procedure category (anterior reference)

Anterior/FOA

Mid/posterior

Total

Procedure category (mid reference)

Mid/posterior

$$
<0.001
$$

$\begin{array}{llll}1,377 & 32.3 & 26.7 & 38.5\end{array}$

$\begin{array}{lll}437 & 21.7 \quad 21.5\end{array}$

26.6

29.7

49.9

20.3

35.2

$<0.001$

$<0.001$

$\begin{array}{llll}605 & 34.8 & 27.9 & 39.3\end{array}$

$\begin{array}{llll}605 & 31.3 & 27.1 & 31.5\end{array}$

$\begin{array}{lll}604 & 23.1 & 20.8\end{array}$

26.6

30.0

51.4

$24.0 \quad 41.3$

$<0.001$

20.5

34.8

$<0.001$

$\begin{array}{lll}710 & 30.1 & 27.3\end{array}$

$\begin{array}{lll}1,104 & 29.5 & 25.0\end{array}$

0.1

$\begin{array}{lll}198 & 29.9 & 23.9\end{array}$

$\begin{array}{lll}301 & 33.5 & 30.0\end{array}$

$\begin{array}{lll}1,315 & 28.8 \quad 25.1\end{array}$

$\begin{array}{lll}1,469 & 30.2 \quad 26.3\end{array}$

$\begin{array}{lll}321 & 28.4 & 24.9\end{array}$

$<0.001$

$\begin{array}{lll}1,290 & 27.6 & 23.7\end{array}$

28.8

22.2

37.7

$\begin{array}{lll}509 & 35.1 & 30.4\end{array}$

35.5

27.4

46.1

0.002

$\begin{array}{llll}1,759 & 29.3 & 25.6 & 28.2\end{array}$

$\begin{array}{llll}55 & 43.9 & 33.0 & 36.2\end{array}$

$22.2 \quad 35.9$

$26.0 \quad 50.4$

0.08

$<0.001$

$\begin{array}{llll}1,562 & 30.6 & 25.9 & 31.8\end{array}$

24.3

41.3

$\begin{array}{lll}252 & 24.6 & 25.5\end{array}$

32.5

24.8

42.5

0.95

0.13

$\begin{array}{lll}847 & 30.2 & 25.0\end{array}$

$\begin{array}{lll}840 & 29.6 & 27.2\end{array}$

$\begin{array}{lll}1,366 & 29.2 & 24.5\end{array}$

$\begin{array}{lll}448 & 31.5 & 29.7\end{array}$

$\begin{array}{lll}1,323 & 29.7 & 26.2\end{array}$

$\begin{array}{lll}448 & 29.7 & 24.7\end{array}$

$\begin{array}{lll}1,537 & 29.7 & 26.4\end{array}$

$\begin{array}{lll}13 & 27.7 & 20.3\end{array}$

0.91

\begin{tabular}{|c|c|c|c|c|c|c|}
\hline \multicolumn{7}{|c|}{$<0.001$} \\
\hline 1,128 & 32.0 & 27.5 & 31.8 & 24.3 & 41.7 & \\
\hline 489 & 24.8 & 21.9 & 29.7 & 22.9 & 38.9 & 0.21 \\
\hline 197 & 28.9 & 24.2 & 34.8 & 26.3 & 46.5 & 0.24 \\
\hline \multicolumn{7}{|c|}{$<0.001$} \\
\hline 489 & 24.8 & 21.9 & 29.7 & 22.9 & 38.9 & \\
\hline
\end{tabular}

0.96 
Table 3 continued

\begin{tabular}{|c|c|c|c|c|c|c|c|c|}
\hline & \multicolumn{4}{|c|}{ Univariable } & \multicolumn{4}{|l|}{ Multivariable } \\
\hline & $n$ & Mean & $\mathrm{SD}^{a}$ & $P$ value & $\begin{array}{l}\text { Adjusted mean in } \\
\text { (count })^{b}\end{array}$ & $\begin{array}{l}\text { lower } 95 \% \\
\mathrm{CI}^{c}\end{array}$ & $\begin{array}{l}\text { upper } 95 \% \\
\mathrm{CI}^{c}\end{array}$ & $P$ value \\
\hline Anterior/FOA & 1,128 & 32.0 & 27.5 & & 31.8 & 24.3 & 41.7 & 0.21 \\
\hline Total & 197 & 28.9 & 24.2 & & 34.8 & 26.3 & 46.5 & 0.07 \\
\hline Procedure category (total reference) & & & & $<0.001$ & & & & \\
\hline Total & 197 & 28.9 & 24.2 & & 34.8 & 26.3 & 46.5 & \\
\hline Anterior/FOA & 1,128 & 32.0 & 27.5 & & 31.8 & 24.3 & 41.7 & 0.24 \\
\hline Mid/posterior & 489 & 24.8 & 21.9 & & 29.7 & 22.9 & 38.9 & 0.07 \\
\hline Distractor placement & & & & $<0.001$ & & & & \\
\hline No & 1,600 & 30.4 & 25.6 & & 36.9 & 28.8 & 47.9 & \\
\hline Yes & 214 & 25.0 & 27.9 & & 27.7 & 20.9 & 36.6 & $<0.001$ \\
\hline Prior craniofacial surgery & & & & 0.87 & & & & \\
\hline No & 1,444 & 29.5 & 25.0 & & & & & \\
\hline Yes & 370 & 30.7 & 29.4 & & & & & \\
\hline Duration of surgery median split (min) & & & & $<0.001$ & & & & \\
\hline Below median (44-225) & 883 & 24.7 & 22.0 & & 25.8 & 19.7 & 33.4 & \\
\hline Above median (226-725) & 887 & 35.2 & 28.5 & & 40.0 & 30.9 & 51.9 & $<0.001$ \\
\hline Intraoperative vasoactive infusion & & & & 0.011 & & & & \\
\hline No & 1668 & 29.0 & 24.5 & & 28.2 & 21.8 & 36.6 & \\
\hline Yes & 146 & 38.6 & 37.3 & & 36.2 & 27.4 & 48.4 & 0.006 \\
\hline $\begin{array}{l}\text { Major intraoperative cardiorespiratory } \\
\text { complication }\end{array}$ & & & & $<0.001$ & & & & \\
\hline No & 1,728 & 29.0 & 25.0 & & 27.4 & 21.3 & 35.5 & \\
\hline Yes & 86 & 43.6 & 37.5 & & 37.3 & 27.7 & 50.4 & $<0.001$ \\
\hline \multicolumn{9}{|l|}{ Blood conservation variable } \\
\hline Deliberate hypotension & & & & 0.35 & & & & \\
\hline No & 1,734 & 29.6 & 25.8 & & & & & \\
\hline Yes & 80 & 32.6 & 28.6 & & & & & \\
\hline EPO use & & & & 0.31 & & & & \\
\hline No & 1,804 & 29.7 & 25.6 & & & & & \\
\hline Yes & 10 & 38.8 & 65.7 & & & & & \\
\hline Cell saver & & & & $<0.001$ & & & & \\
\hline No & 1,535 & 31.7 & 25.8 & & 31.8 & 24.5 & 41.3 & \\
\hline Yes & 279 & 18.7 & 23.8 & & 32.5 & 23.6 & 44.3 & 0.95 \\
\hline Antifibrinolytic & & & & $<0.001$ & & & & \\
\hline No & 564 & 26.9 & 26.2 & & 34.8 & 26.6 & 46.1 & \\
\hline Yes & 1,214 & 31.3 & 25.6 & & 29.4 & 22.6 & 38.1 & 0.009 \\
\hline Intraoperative $\mathbf{R B C}$ protocol & & & & $<0.001$ & & & & \\
\hline No & 1,227 & 26.9 & 23.3 & & 30.0 & 23.1 & 39.3 & \\
\hline Yes & 587 & 35.7 & 29.9 & & 34.1 & 25.8 & 45.6 & 0.17 \\
\hline
\end{tabular}

${ }^{\text {a }} \mathrm{SD}=$ standard deviation, ${ }^{b}$ Predicted intraoperative red blood cell $(\mathrm{RBC})$-containing product transfusion $\left(\mathrm{mL} \cdot \mathrm{kg}^{-1}\right)$ for each independent variable based on the multivariable model, ${ }^{c} \mathrm{CI}=$ confidence interval.; $\mathrm{EPO}=$ erythropoietin; FOA $=$ fronto-orbital advancement; ICP $=$ intracranial pressure; ICU = intensive care unit; $\mathrm{PACU}=$ postanesthesia care unit; $\mathrm{T}=$ temperature

complexity of these procedures. Interestingly, none of the blood conservation variables were associated with a greater number of blood donor exposures, suggesting that the effects of patient and procedural variables predominated.
Transfusion-free hospital course

Achieving a safe, transfusion-free hospital course is a laudable goal. We found that increasing age, increasing body weight, and higher preoperative hematocrit were each 
Table 4 Univariable and multivariable analyses for the outcome "total perioperative blood donor exposures" among patients of all ages

\begin{tabular}{|c|c|c|c|c|c|c|c|c|}
\hline & \multicolumn{4}{|c|}{ Univariable } & \multicolumn{4}{|l|}{ Multivariable } \\
\hline & $n$ & Mean & $\mathrm{SD}^{a}$ & $P$ value & $\begin{array}{l}\text { Adjusted mean } \\
\text { in (count })^{b}\end{array}$ & $\begin{array}{l}\text { lower } \\
95 \% \mathrm{CI}^{c}\end{array}$ & $\begin{array}{l}\text { upper } \\
95 \% \mathrm{CI}^{c}\end{array}$ & $P$ value \\
\hline \multicolumn{9}{|l|}{ Patient variable } \\
\hline Age & & & & 0.005 & & & & \\
\hline$\leq 24$ months & 1,377 & 1.8 & 1.7 & & 3.0 & 2.4 & 3.7 & \\
\hline$>24$ months & 437 & 1.8 & 2.4 & & 2.5 & 2.0 & 3.2 & 0.003 \\
\hline Weight $(\mathrm{kg})$ tertile & & & & 0.22 & & & & \\
\hline $1(3.2-8.56)$ & 604 & 1.8 & 1.6 & & & & & \\
\hline $2(8.57-10.9)$ & 605 & 1.8 & 1.7 & & & & & \\
\hline $3(11-129)$ & 605 & 1.9 & 2.2 & & & & & \\
\hline Sex & & & & 0.41 & & & & \\
\hline Female & 710 & 1.8 & 2.1 & & & & & \\
\hline Male & 1,104 & 1.8 & 1.7 & & & & & \\
\hline Race (black reference) & & & & 0.001 & & & & \\
\hline Black/African American & 198 & 2.0 & 1.8 & & 2.7 & 2.1 & 3.5 & \\
\hline Other & 301 & 2.0 & 2.0 & & 2.6 & 2.1 & 3.2 & 0.30 \\
\hline White & 1,315 & 1.7 & 1.8 & & 2.9 & 2.3 & 3.7 & 0.47 \\
\hline Race (white reference) & & & & 0.001 & & & & \\
\hline White & 1,315 & 1.7 & 1.8 & & 2.9 & 2.3 & 3.7 & \\
\hline Black/African American & 198 & 2.0 & 1.8 & & 2.7 & 2.1 & 3.5 & 0.7 \\
\hline Other & 301 & 2.0 & 2.0 & & 2.6 & 2.1 & 3.2 & 0.019 \\
\hline Race (other reference) & & & & 0.001 & & & & \\
\hline Other & 301 & 2.0 & 2.0 & & 2.6 & 2.1 & 3.2 & \\
\hline Black/African American & 198 & 2.0 & 1.8 & & 2.7 & 2.1 & 3.5 & 0.30 \\
\hline White & 1,315 & 1.7 & 1.8 & & 2.9 & 2.3 & 3.7 & 0.02 \\
\hline Ethnicity & & & & 0.54 & & & & \\
\hline Non-Hispanic & 1,469 & 1.8 & 1.8 & & & & & \\
\hline Hispanic & 321 & 1.8 & 2.1 & & & & & \\
\hline ASA physical status & & & & $<0.001$ & & & & \\
\hline I-II & 228 & 1.6 & 1.5 & & 2.4 & 1.9 & 3.0 & \\
\hline III-IV & 1,062 & 2.3 & 2.5 & & 3.1 & 2.5 & 3.9 & 0.05 \\
\hline Tracheostomy & & & & 0.001 & & & & \\
\hline No & 1,759 & 1.8 & 1.8 & & 2.2 & 1.8 & 2.8 & \\
\hline Yes & 55 & 3.4 & 3.6 & & 3.4 & 2.6 & 4.3 & $<0.001$ \\
\hline Preoperative elevated ICP & & & & 0.33 & & & & \\
\hline No & 1,562 & 1.8 & 1.8 & & & & & \\
\hline Yes & 252 & 1.9 & 2.3 & & & & & \\
\hline Preoperative hematocrit median split (\%) & & & & 0.6 & & & & \\
\hline Below median (22-35.7) & 847 & 1.8 & 1.6 & & & & & \\
\hline Above median (35.8-52) & 840 & 1.9 & 2.1 & & & & & \\
\hline Syndromic/multi-suture synostosis & & & & 0.004 & & & & \\
\hline No & 1,366 & 1.7 & 1.7 & & 2.7 & 2.1 & 3.4 & \\
\hline Yes & 448 & 2.1 & 2.3 & & 2.8 & 2.2 & 3.5 & 0.40 \\
\hline Intraoperative hypothermia $(\mathrm{T}<35)$ & & & & 0.61 & & & & \\
\hline No & 1,323 & 1.8 & 1.9 & & & & & \\
\hline Yes & 448 & 1.8 & 1.8 & & & & & \\
\hline Hypothermia on arrival to ICU/PACU $(\mathrm{T}<35)$ & & & & 0.78 & & & & \\
\hline No & 1,537 & 1.8 & 1.9 & & & & & \\
\hline
\end{tabular}


Table 4 continued

\begin{tabular}{|c|c|c|c|c|c|c|c|c|}
\hline & \multicolumn{4}{|c|}{ Univariable } & \multicolumn{4}{|l|}{ Multivariable } \\
\hline & $n$ & Mean & $\mathrm{SD}^{a}$ & $P$ value & $\begin{array}{l}\text { Adjusted mean } \\
\text { in (count })^{b}\end{array}$ & $\begin{array}{l}\text { lower } \\
95 \% \mathrm{CI}^{c}\end{array}$ & $\begin{array}{l}\text { upper } \\
95 \% \mathrm{CI}^{c}\end{array}$ & $P$ value \\
\hline Yes & 13 & 2.2 & 3.1 & & & & & \\
\hline \multicolumn{9}{|l|}{ Procedure variable } \\
\hline Procedure category (anterior reference) & & & & $<0.001$ & & & & \\
\hline Anterior/FOA & 1,128 & 1.9 & 2.0 & & 2.7 & 2.1 & 3.3 & \\
\hline Mid/posterior & 489 & 1.5 & 1.4 & & 2.5 & 2.0 & 3.2 & 0.31 \\
\hline Total & 197 & 2.0 & 2.0 & & 3.1 & 2.4 & 3.9 & 0.04 \\
\hline Procedure category (mid reference) & & & & $<0.001$ & & & & \\
\hline Mid/posterior & 489 & 1.5 & 1.4 & & 2.5 & 2.0 & 3.2 & \\
\hline Anterior/FOA & 1,128 & 1.9 & 2.0 & & 2.7 & 2.1 & 3.3 & 0.31 \\
\hline Total & 197 & 2.0 & 2.0 & & 3.1 & 2.4 & 3.9 & 0.02 \\
\hline Procedure category (total reference) & & & & $<0.001$ & & & & \\
\hline Total & 197 & 2.0 & 2.0 & & 3.1 & 2.4 & 3.9 & \\
\hline Anterior/FOA & 1,128 & 1.9 & 2.0 & & 2.7 & 2.1 & 3.3 & 0.04 \\
\hline Mid/posterior & 489 & 1.5 & 1.4 & & 2.5 & 2.0 & 3.2 & 0.02 \\
\hline Distractor placement & & & & $<0.001$ & & & & \\
\hline No & 1,600 & 1.9 & 1.9 & & 3.1 & 2.5 & 3.8 & \\
\hline Yes & 214 & 1.4 & 1.5 & & 2.5 & 1.9 & 3.1 & 0.003 \\
\hline Prior craniofacial surgery & & & & 0.03 & & & & \\
\hline No & 1,444 & 1.7 & 1.7 & & 2.6 & 2.1 & 3.3 & \\
\hline Yes & 370 & 2.2 & 2.4 & & 2.9 & 2.3 & 3.6 & 0.05 \\
\hline Duration of surgery median split (minutes) & & & & $<0.001$ & & & & \\
\hline Below median (44-225) & 883 & 1.3 & 1.0 & & 2.2 & 1.8 & 2.8 & \\
\hline Above median (226-725) & 887 & 2.3 & 2.3 & & 3.4 & 2.7 & 4.2 & $<0.001$ \\
\hline Intraoperative vasoactive infusion & & & & $<0.001$ & & & & \\
\hline No & 1,668 & 1.7 & 1.7 & & 2.2 & 1.8 & 2.8 & \\
\hline Yes & 146 & 2.7 & 3.0 & & 3.4 & 2.6 & 4.3 & $<0.001$ \\
\hline Major intraoperative cardiorespiratory complication & & & & $<0.001$ & & & & \\
\hline No & 1,728 & 1.8 & 1.8 & & 2.5 & 2.0 & 3.1 & \\
\hline Yes & 86 & 2.6 & 2.4 & & 3.0 & 2.3 & 3.8 & 0.03 \\
\hline \multicolumn{9}{|l|}{ Blood conservation variable } \\
\hline Deliberate hypotension & & & & 0.60 & & & & \\
\hline No & 1,734 & 1.8 & 1.8 & & & & & \\
\hline Yes & 80 & 1.9 & 2.4 & & & & & \\
\hline EPO use & & & & 0.83 & & & & \\
\hline No & 1,804 & 1.8 & 1.8 & & & & & \\
\hline Yes & 10 & 2.9 & 4.2 & & & & & \\
\hline Cell saver & & & & $<0.001$ & & & & \\
\hline No & 1,535 & 1.9 & 1.9 & & 2.4 & 2.0 & 3.0 & \\
\hline Yes & 279 & 1.2 & 1.7 & & 3.1 & 2.3 & 4.1 & 0.05 \\
\hline Antifibrinolytic & & & & 0.005 & & & & \\
\hline No & 564 & 1.8 & 2.0 & & 2.9 & 2.3 & 3.7 & \\
\hline Yes & 1,214 & 1.9 & 1.8 & & 2.6 & 2.1 & 3.2 & 0.03 \\
\hline Intraoperative RBC protocol & & & & 0.12 & & & & \\
\hline No & 1,227 & 1.9 & 2.1 & & & & & \\
\hline Yes & 587 & 1.6 & 1.4 & & & & & \\
\hline
\end{tabular}


Table 4 continued

\begin{tabular}{|c|c|c|c|c|c|c|c|c|}
\hline & \multicolumn{4}{|c|}{ Univariable } & \multicolumn{4}{|l|}{ Multivariable } \\
\hline & $n$ & Mean & $\mathrm{SD}^{a}$ & $P$ value & $\begin{array}{l}\text { Adjusted mean } \\
\text { in (count) })^{b}\end{array}$ & $\begin{array}{l}\text { lower } \\
95 \% \mathrm{CI}^{c}\end{array}$ & $\begin{array}{l}\text { upper } \\
95 \% \mathrm{CI}^{c}\end{array}$ & $P$ value \\
\hline Postoperative transfusion protocol & & & & 0.003 & & & & \\
\hline No & 1,318 & 1.9 & 2.0 & & 2.8 & 2.3 & 3.5 & \\
\hline Yes & 496 & 1.5 & 1.3 & & 2.7 & 2.1 & 3.5 & 0.53 \\
\hline
\end{tabular}

Table 5 Univariable and multivariable analyses for the binary outcome "transfusion-free hospital course (yes/no)" among patients of all ages

\begin{tabular}{|c|c|c|c|c|c|c|}
\hline Univar & & & Mult & & & \\
\hline $\begin{array}{l}\text { No } \\
n(\%)\end{array}$ & $\begin{array}{l}\text { Yes } \\
n(\%)\end{array}$ & $P$ Value & $\mathrm{OR}^{b}$ & $\begin{array}{l}\text { lower } 95 \% \\
\mathrm{CI}^{c}\end{array}$ & $\begin{array}{l}\text { upper } 95 \% \\
\mathrm{CI}^{c}\end{array}$ & $P$ value \\
\hline
\end{tabular}

\section{Patient variable}

Age

$$
\leq 24 \text { months }
$$

$>24$ months

Weight (kg) rank

$$
\begin{aligned}
& 1 \text { (3.2-8.56) } \\
& 2(8.57-10.9) \\
& 3(11-129)
\end{aligned}
$$

Sex

\section{Female \\ Male}

\section{Race (black reference)}

Black/African American

Other

White

\section{Race (white reference)}

White

Black/African American

Other

\section{Race (other reference)}

Other

Black/African American

White

Ethnicity

Non-Hispanic

Hispanic

\section{ASA physical status}

$$
\text { I-II }
$$

III-IV

Tracheostomy

No

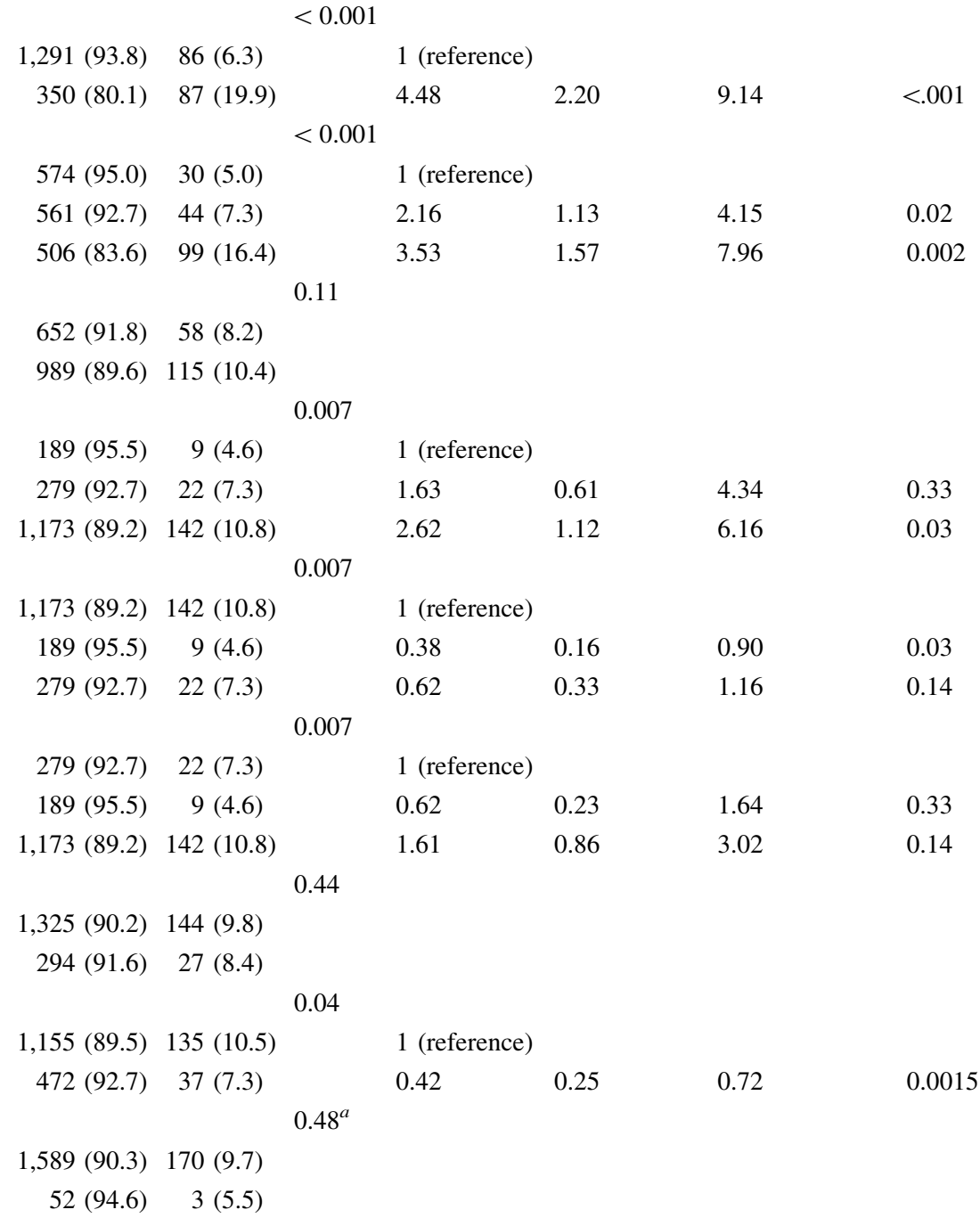


Table 5 continued

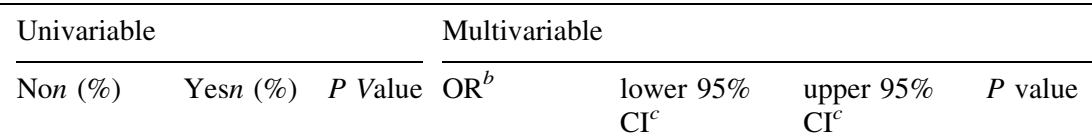

Preoperative elevated ICP

No

Yes

Preoperative hematocrit median split (\%)

Below median (22-35.7)

Above median (35.8-52)

Syndromic/multi-suture synostosis

No

Yes

Intraoperative hypothermia $(T<35)$

No

Yes

Hypothermia on arrival to ICU/PACU $(\mathrm{T}<35)$

No

Yes

Procedure variable

Procedure category (anterior reference)

Anterior/FOA

Mid/posterior

Total

Procedure category (mid reference)

$\mathrm{Mid} /$ posterior

Anterior/FOA

Total

Procedure category (total reference)

Total

Anterior/FOA

Mid/posterior

Distractor placement

No

Yes

Prior craniofacial surgery

No

Yes

Duration of surgery median split (minutes)

Below median (44-225)

Above median (226-725)

Intraoperative vasoactive infusion

No

Yes

Major intraoperative cardiorespiratory complication

No
Yes

$$
\begin{array}{rc}
741(88.2) & 99(11.8) \\
1,239(90.7) & 127(9.3) \\
402(89.7) & 46(10.3) \\
1,190(90.0) & 133(10.1) \\
418(93.3) & 30(6.7) \\
1,389(90.4) & 148(9.6) \\
12(92.3) & 1(7.7)
\end{array}
$$$$
<0.001
$$$$
1,432(91.7) \quad 130(8.3) \quad 1 \text { (reference) }
$$$$
209(82.9) \quad 43(17.1) \quad 1.07 \quad 0.61
$$$$
<0.001
$$$$
801(94.6) \quad 46(5.4) \quad 1 \text { (reference) }
$$$$
2.66 \quad 1.68
$$$$
0.54
$$$$
0.03
$$$$
1 \text { (reference) }
$$$$
0.80
$$$$
0.46
$$

$$
1^{a}
$$

1.37

0.41

$$
0.001
$$

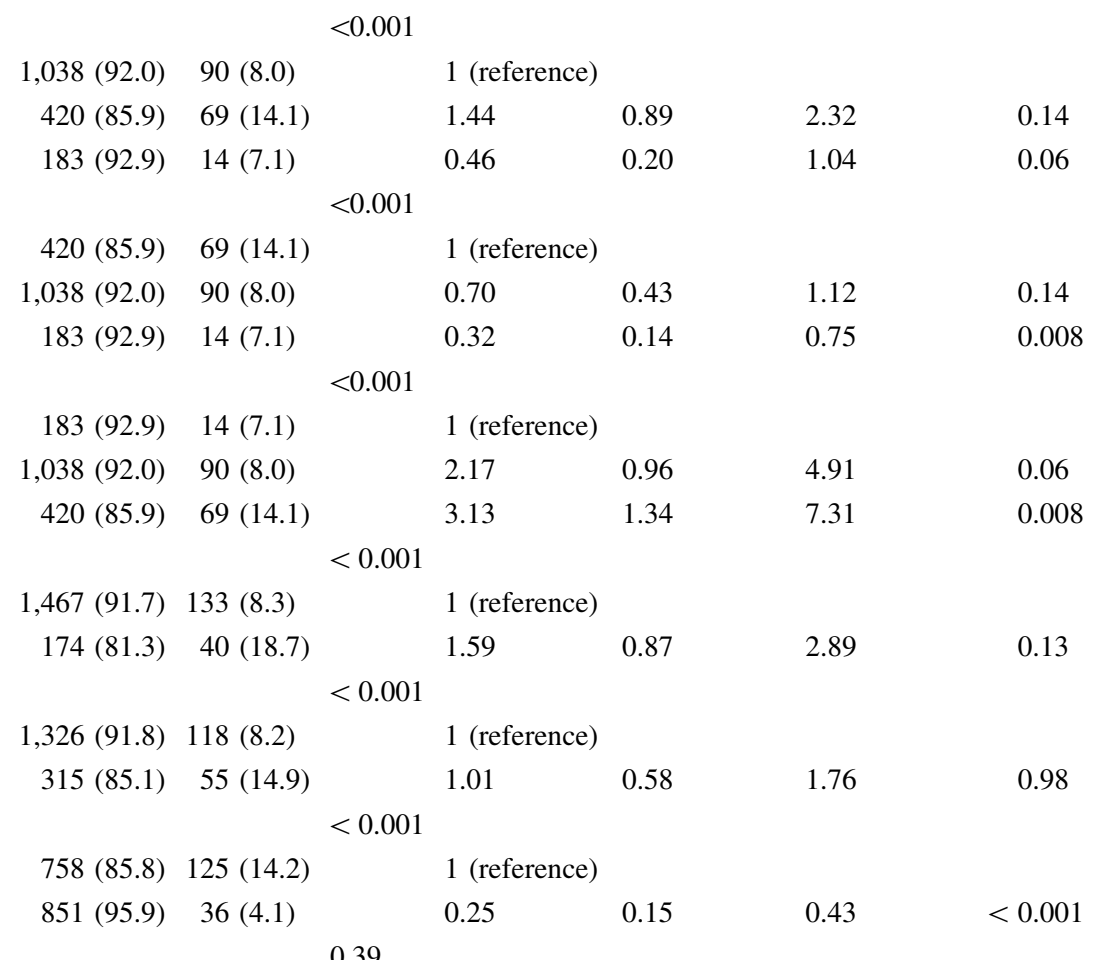

$1,506(90.3) \quad 162(9.7)$

$135(92.5) \quad 11(7.5)$ 
Table 5 continued

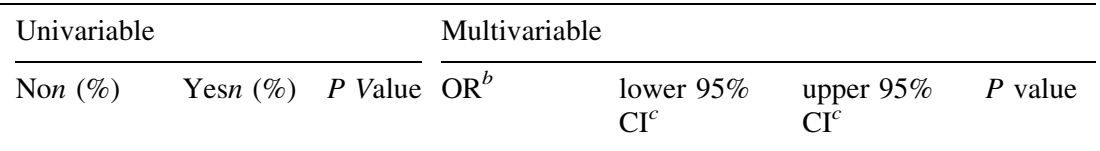

\section{Blood conservation variable}

Deliberate hypotension

No

Yes

Cell saver

No

Yes

Antifibrinolytic

No

Yes

Intraoperative RBC protocol

No

Yes

Postoperative transfusion protocol

No

Yes

\subsection{9}

1,569 (90.5) 165 (9.5)

$72(90.0) \quad 8(10.0)$

$1,427(93.0) \quad 108(7.0) \quad 1$ (reference)

$214(76.7) \quad 65(23.3)$

$\begin{array}{ll}4.62 & 2.77\end{array}$

7.69

$<0.001$

$<0.001$

$491(87.1) \quad 73(12.9) \quad 1$ (reference)

$1,128(92.9) \quad 86(7.1)$

1.39

0.86

2.25

0.18

$<0.001$

$1,075(87.6) \quad 152(12.4)$

1 (reference)

566 (96.4) $21(3.6)$

$0.10 \quad 0.05$

0.21

$<0.001$

$<0.001$

$1,211(91.9) \quad 107(8.1)$

1 (reference)

$430(86.7) \quad 66(13.3)$
1.31

3.81

0.003

${ }^{a}$ Fisher exact test $P$ value was used where expected counts were less than $5,{ }^{b} \mathrm{OR}=$ odds ratio, ${ }^{c} \mathrm{CI}=$ confidence interval; EPO $=$ erythropoietin; $\mathrm{FOA}=$ fronto-orbital advancement; ICP = intracranial pressure; ICU = intensive care unit; PACU = postanesthesia care unit; RBC = red blood cell; $\mathrm{T}=$ temperature

associated with an increased likelihood of a transfusionfree hospitalization. Children with a preoperative hematocrit above the median of $35 \%$ were nearly three times more likely to avoid transfusion. This highlights the potential value of optimizing preoperative hematocrit and treating anemia when present; a concept supported elsewhere in the adult and pediatric perioperative literature. $^{21-24}$

More medically complex patients (ASA physical status III or IV) were less likely to experience a transfusion-free hospital course, similar to data previously reported for pediatric surgical patients. ${ }^{25}$ The only procedural variable associated with a transfusion-free hospitalization was shorter duration of surgery, consistent with our other findings.

Use of cell saver and transfusion protocols were predictive of a transfusion-free hospitalization. Interestingly, despite evidence of efficacy, transfusion protocols are underutilized. ${ }^{10}$ Counterintuitively, intraoperative transfusion protocols were associated with a reduced likelihood of a transfusion-free course. This may be because we did not account for the effect of institution in this outcome, as centres with greater transfusion may also have implemented intraoperative transfusion protocols.
Limitations

Limitations of this study include those inherent to clinical databases including inaccurate or missing data. ${ }^{26}$ Associations and not cause and effect relationships can be established with observational data. Additionally, the registry may not capture all management strategies that have an impact on outcomes. While the effect of institution was accounted for in the RBC-CP transfusion and blood donor exposure analyses, it was not accounted for in the transfusion-free hospitalization outcome because it is a binary variable with a low frequency of occurrence. For this outcome, the effects of variables for which there was little within-institutional heterogeneity could not be separated from institution-specific outcomes. Finally, the number of patients who experienced a transfusion-free hospitalization was small and so conclusions should be drawn cautiously regarding this outcome.

\section{Conclusion}

In this large, multicentre dataset we identified significant predictors of relevant transfusion outcomes in CCVR. The significant demographic variables may help physicians preoperatively identify patients with greater transfusion requirements. Patient variables independently associated 
with increasing blood transfusion included younger age, decreasing weight, and increasing ASA physical status. Procedure-related variables that were associated with increasing blood transfusion included the more complex total cranial vault remodeling procedures, longer surgical duration, use of a vasoactive infusion intraoperatively, and the occurrence of a major intraoperative cardiorespiratory complication. Lack of antifibrinolytic administration was the only blood conservation variable independently associated with higher blood transfusion. Our findings of increased blood donor exposures for longer procedures and total cranial vault reconstruction and reduced transfusion with procedures involving distractor application provide information to be considered in surgical planning. Some of the identified predictors are directly modifiable and can serve as substrates for future investigation of improvement efforts.

Acknowledgements Collaborators for the Pediatric Craniofacial Collaborative Group: Christopher Abruzzese, DO, cabruzz1@ jhmi.edu; Jesus Apuya, MD, apuyajesus@uams.edu; Amy Beethe, MD, abeethe@childrensomaha.org; Hubert Benzon, MD, HBenzon@ luriechildrens.org; Wendy Binstock, MD, WBinstock@dacc.uchicago. edu; Alyssa Brzenski, MD, abrzenski@ucsd.edu; Stefan Budac, MD, Stefan.budac@seattlechildrens.org; Veronica Busso, MD, Veronica. Busso@cchmc.org; Surendrasingh Chhabada, MD, chhabas@ccf.org; Franklin Chiao, MD, fchiao@gmail.com; Franklyn Cladis, MD, cladfp@anes.upmc.edu; Danielle Claypool, MD, dclaypoo@mcw.edu; Michael Collins, MD, Michael.collins@seattlechildrens.org; Andrew Costandi, MD, acostandi@chla.usc.edu; Rachel Dabek, Rachel.dabek@ childrens.harvard.edu; Nicholas Dalesio, MD, ndalesi1@jhmi.edu; Ricardo Falcon, MD, rfalcon@salud.unm.edu; Allison Fernandez, MD, aferna27@jhmi.edu; John Fiadjoe, MD, fiadjoej@email. chop.edu; Katherine Gentry, MD, Katherine.gentry@ seattlechildrens. org; Chris Glover, MD, cdglover@texaschildrens.org; Amanda Gosman, MD, agosman@ucsd.edu; Shannon Grap, MD, sgrap@ hmc.psu.edu; Heike Gries, MD, griesh@ohsu.edu; Allison Griffin, Allison.Griffin@UTSouthwestern.edu; Charles Haberkern, MD, charles.haberkern@seattlechildrens.org; John Hajduk, BS, JHajduk@ luriechildrens.org; Rebecca Hall, MD, hallreb@ohsu.edu; Jennifer Hansen, MD, jhansen4@kumc.edu; Mali Hetmaniuk, MD, Mali. Hetmaniuk@seattlechildrens.org; Vincent Hsieh, MD, vincent.hsieh@ seattlechildrens.org; Henry Huang, MD, hxhuang@texaschildrens.org; Pablo Ingelmo, MD, Pablo.Ingelmo@MUHC.MCGILL.CA; Iskra Ivanova, MD, Iskra.ivanova@seattlechildrens.org; Ranu Jain, MD, Ranu.Jain@uth.tmc.edu; Siri Kanmanthreddy, MD, siri. kanmanthreddy@seattlechildrens.org; Michelle Kars, MD, Mkars@ northwell.edu; Michael R. King, MicKing@luriechildrens.org; Courtney Kowalczyk-Derderian, MD, Courtney.Derderian@ childrens.com; Kristen Labovsky, MD, klabovsky@mcw.edu; Indrani Lakheeram, MD, i.lakheeram@gmail.com; Andrew Lee, adlee@ texaschildrens.org; Jose Luis Martinez, MD, jose.luis.martinez.hsj@ ssssgouv.qc.ca; Brian Masel, MD, bdmasel@uams.edu; Eduardo Medellin, exmedell@texaschildrens.org; Petra Meier, MD, Petra. MEIER-HARAN@childrens.harvard.edu; Heather Mitzel Levy, MD, hlevy@kumc.edu; Wallis T. Muhly, MD, muhlyw@email.chop.edu; Bridget Muldowney, MD, blmuldowney@wisc.edu; Jonathon Nelson, JNelson@childrensnational.org; Julie Nicholson, jenichol@ texaschildrens.org; Kim-Phuong Nguyen, kpnguyen@texaschildrens. org; Thanh Nguyen, MD, thanh.t.nguyen.1@ vanderbilt.edu; Olutoyin A. Olutuye, MD, oaolutoy@texaschildrens.org; Margaret Owens-
Stubblefield, mxowenss@texaschildrens.org; Uma Ramesh Parekh, uparekh@hmc.psu.edu; Roshan Patel, MD, roshapat@montefiore.org; Timothy Petersen, PhD, timpetersen@salud.unm.edu; Vanessa Pohl, vpohl@phoenixchildrens.com; Julian Post, Julian.post@childrens. harvard.edu; Kim Poteet-Schwartz, MD, KLPoteetschwartz@ uams.edu; Srijaya Reddy, MD, Srijaya.k.reddy@vanderbilt.edu; Russell Reid, MD, rreid@surgery.bsd.uchicago.edu; Karene Ricketts, MD, kricketts@aims.unc.edu; Laura Ryan MD, lwryan@ texaschildrens.org; Peggy Seidman, MD, Peggy.Seidman@ UHhospitals.org; Davinder Singh, dsingh@phoenixchildrens.com; Neil R. Singhal, rajusinghal@gmail.com; Codruta Soneru, MD, csoneru@salud.unm.edu; Emad Sorial, MD, Emad.M.Sorial@ uth.tmc.edu; Rachel Spitznagel, MD, rspitznagel@childrensomaha. org; Bobbie Stubbeman, BS, Bobbie.Stubbeman@cchmc.org; Rani Sunder, MD, rani.sunder@seattlechildrens.org; Wai Sung, MD, sungw@ccf.org; Tariq Syed, MS, Tariq.A.Syed@uth.tmc.edu; Peter Szmuk, MD, pszmuk@gmail.com; Douglas Thompson, MD, drthompson@wustl.edu; Galit Ungar-Kastner MD, galit.ungarkastner@childrens.com; Rheana Watts, CRNA, rheana.watts@ seattlechildrens.org; John Wieser, JWieser@luriechildrens.org; Karen Wong, MBBS, karen.wong@ seattlechildrens.org; Lillian Zamora, lzamora1@jhmi.edu.

\section{Conflicts of interest None declared.}

Editorial responsibility This submission was handled by Dr. Philip M. Jones, Associate Editor, Canadian Journal of Anesthesia.

Author contributions Patrick G. Fernandez and Brad M. Taicher helped design the study, collect and analyze the data, and write the manuscript. Susan M. Goobie helped collect and analyze the data, and write the manuscript. Meera Gangadharan helped collect and analyze the data, prepare tables, and write the manuscript. H. Mayumi Homi, Jane Kugler, and Rochelle Skit helped collect and analyze data, and prepare the tables. Lingyu Cai and Marcia Polansky performed the statistical analysis. Paul A Stricker helped conceive the study idea, design the study, collect and analyze the data, and write the manuscript. The Pediatric Craniofacial Collaborative Group authors contributed to the data registry from which our data was gathered.

Financial sources Support was provided solely from institutional and/or departmental sources.

\section{References}

1. Zou S, Dorsey KA, Notari EP, et al. Prevalence, incidence, and residual risk of human immunodeficiency virus and hepatitis $C$ virus infections among United States blood donors since the introduction of nucleic acid testing. Transfusion 2010; 50: 1495504.

2. Zou S, Stramer SL, Notari EP, et al. Current incidence and residual risk of hepatitis $\mathrm{B}$ infection among blood donors in the United States. Transfusion 2009; 49: 1609-20.

3. Lavoie J. Blood transfusion risks and alternative strategies in pediatric patients. Paediatr Anaesth 2011; 21: 14-24.

4. Chang CM, Quinlan SC, Warren JL, Engels EA. Blood transfusions and the subsequent risk of hematologic malignancies. Transfusion 2010; 50: 2249-57.

5. Bilgin $Y M$, van de Watering $L M$, Eijsman $L$, Versteegh MI, van Oers $M H$, Brand A. Is increased mortality associated with post- 
operative infections after leukocytes containing red blood cell transfusions in cardiac surgery? An extended analysis. Transfus Med 2007; 17: 304-11.

6. Stainsby D, Jones H, Wells AW, Gibson B, Cohen H, Group SS. Adverse outcomes of blood transfusion in children: analysis of UK reports to the serious hazards of transfusion scheme 19962005. Br J Haematol 2008; 141: 73-9.

7. White N, Bayliss S, Moore D. Systematic review of interventions for minimizing perioperative blood transfusion for surgery for craniosynostosis. J Craniofac Surg 2015; 26: 26-36.

8. von Elm E, Altman DG, Egger M, et al. The Strengthening the Reporting of Observational Studies in Epidemiology (STROBE) Statement: guidelines for reporting observational studies. Int $\mathbf{J}$ Surg 2014; 12: 1495-9.

9. Harris PA, Taylor R, Thielke R, Payne J, Gonzalez N, Conde JG. Research electronic data capture (REDCap)-a metadata-driven methodology and workflow process for providing translational research informatics support. J Biomed Inform 2009; 42: 377-81.

10. Stricker PA, Goobie SM, Cladis FP, et al. Perioperative outcomes and management in pediatric complex cranial vault reconstruction: a multicenter study from the Pediatric Craniofacial Collaborative Group. Anesthesiology 2017; 126: 276-87.

11. Stricker PA, Fiadjoe JE, Davis AR, et al. Reconstituted blood reduces blood donor exposures in children undergoing craniofacial reconstruction surgery. Paediatr Anaesth 2011; 21: 54-61.

12. Chow I, Purnell CA, Gosain AK. Assessing the impact of blood loss in cranial vault remodeling: a risk assessment model using the 2012 to 2013 Pediatric National Surgical Quality Improvement Program data sets. Plast Reconstr Surg 2015; 136: $1249-60$.

13. White $N$, Marcus $R$, Dover $S$, et al. Predictors of blood loss in front-orbital advancement and remodeling. J Craniofac Surg 2009; 20: 378-81.

14. Stricker PA, Shaw TL, Desouza DG, et al. Blood loss, replacement, and associated morbidity in infants and children undergoing craniofacial surgery. Paediatr Anaesth 2010; 20: 1509.

15. Goobie SM, Zurakowski D, Proctor MR, et al. Predictors of clinically significant postoperative events after open craniosynostosis surgery. Anesthesiology 2015; 122: 1021-32.

16. Goobie SM, Meier PM, Pereira LM, et al. Efficacy of tranexamic acid in pediatric craniosynostosis surgery: a double-blind, placebo-controlled trial. Anesthesiology 2011; 114: 862-71.
17. Dadure $C$, Sauter $M$, Bringuier $S$, et al. Intraoperative tranexamic acid reduces blood transfusion in children undergoing craniosynostosis surgery: a randomized double-blind study. Anesthesiology 2011; 114: 856-61.

18. Oppenheimer AJ, Ranganathan $K$, Levi B, et al. Minimizing transfusions in primary cranial vault remodeling: the role of aminocaproic acid. J Craniofac Surg 2014; 25: 82-6.

19. Hsu G, Taylor JA, Fiadjoe JE, et al. Aminocaproic acid administration is associated with reduced perioperative blood loss and transfusion in pediatric craniofacial surgery. Acta Anaesthesiol Scand 2016; 60: 158-65.

20. Goobie SM, Cladis FP, Glover CD, et al. Safety of antifibrinolytics in cranial vault reconstructive surgery: a report from the pediatric craniofacial collaborative group. Pediatr Aaesth 2017; 27: 271-81.

21. Litton E, Xiao J, Ho KM. Safety and efficacy of intravenous iron therapy in reducing requirement for allogenic blood transfusion: systematic review and meta-analysis of randomised clinical trials. BMJ 2013; 347: f4822.

22. Alexander DP, Frew N. Preoperative optimisation of anaemia for primary total hip arthroplasty: a systematic review. Hip Int 2017; 27: 515-22.

23. Goobie SM, Faraoni D, Zurakowski D, DiNardo JA. Association of Preoperative Anemia With Postoperative Mortality in Neonates. JAMA Pediatr 2016; 170: 855-62.

24. Faraoni D, DiNardo JA, Goobie SM. Relationship between preoperative anemia and in-hospital mortality in children undergoing noncardiac surgery. Anesth Analg 2016; 123: 1582-7.

25. Sathiyakumar V, Estevez-Ordonez D, Thakore $R V$, et al. American Society of Anesthesiologists score as a predictive tool to optimize blood ordering for intraoperative transfusion in orthopaedic trauma cases. J Surg Orthop Adv 2016; 25: 105-9.

26. Levin PE. Apples, oranges, and national databases: commentary on an article by Daniel D. Bohl, MPH, et al.: "Variations in data collection methods between national databases affect study results: a comparison of the nationwide inpatient sample and national surgical quality improvement program databases for lumbar spine fusion procedures". J Bone Joint Surg Am 2014; 96 : e198.

Publisher's Note Springer Nature remains neutral with regard to jurisdictional claims in published maps and institutional affiliations. 